\title{
Article \\ Microstructural and Hardness Behavior of H13 Tool Steel Manufactured by Ultrasound-Assisted Laser-Directed Energy Deposition
}

\author{
Dmitriy Masaylo $^{1, *}$, Sergei Igoshin ${ }^{1}$, Anatoly Popovich ${ }^{1}$, Alexey Orlov ${ }^{1}$, Artem Kim $^{1}$ and Vera Popovich ${ }^{1,2}$ \\ 1 Institute of Mechanical Engineering of Materials and Transport, Peter the Great St. Petersburg Polytechnic \\ University, 194064 Saint-Petersburg, Russia; igoshin_sd@spbstu.ru (S.I.); director@immet.spbstu.ru (A.P.); \\ orlov-av@spbstu.ru (A.O.); kim.ae@edu.spbstu.ru (A.K.); v.popovich@tudelft.nl (V.P.) \\ 2 Department of Materials Science and Engineering, Delft University of Technology, \\ 2628 CN Delft, The Netherlands \\ * Correspondence: masajlo_dv@spbstu.ru
}

Citation: Masaylo, D.; Igoshin, S.; Popovich, A.; Orlov, A.; Kim, A.; Popovich, V. Microstructural and Hardness Behavior of H13 Tool Steel Manufactured by UltrasoundAssisted Laser-Directed Energy Deposition. Metals 2022, 12, 450. https://doi.org/10.3390/met12030450

Academic Editor: Amir Mostafaei

Received: 26 January 2022

Accepted: 2 March 2022

Published: 5 March 2022

Publisher's Note: MDPI stays neutral with regard to jurisdictional claims in published maps and institutional affiliations.

Copyright: (C) 2022 by the authors. Licensee MDPI, Basel, Switzerland. This article is an open access article distributed under the terms and conditions of the Creative Commons Attribution (CC BY) license (https:// creativecommons.org/licenses/by/ $4.0 /)$.

\begin{abstract}
Metal additive manufacturing (AM) by Laser-Directed Energy Deposition (L-DED) usually results in the formation of textured columnar grains along the build direction, leading to anisotropic mechanical properties. This can negatively affect the intended application of the product. Anisotropy can be eliminated by modifying the material through an additional exposure to ultrasound (USassisted) during the L-DED process. In this paper, a multi-track sample was manufactured from AISI H13 (TLS Technik, Bitterfeld-Wolfen, Germany) tool steel by a US-assisted ( $28 \mathrm{kHz}$ ) L-DED process using a specially designed cooling system. The study also included post-process annealing and quenching with the tempering heat treatment of the modified steel, resulting in the retention of the properties, as confirmed by hardness measurements. XRD analysis was used to measure the structural parameters of the unit cell, and the hardness properties were measured in two directions: longitudinally and parallel to the deposition direction. It was found that US-assisted L-DED allows us to obtain a more isotropic structure with an equal size of the coherent scattering region in two printing directions, and to reduce the residual stresses in the material. The anisotropy of the hardness was significantly reduced, with 636 and $640 \mathrm{HV}$ found between the XY and XZ planes. Based on the obtained hardness data, it should be noted that some of the heat treatments studied herein can also result in a decrease in the anisotropy of the properties, similarly to the US-assisted effect.
\end{abstract}

Keywords: additive manufacturing; US-assisted; laser-directed energy deposition; anisotropy; columnar grains; H13 tool steel

\section{Introduction}

In this work, an in-situ method for changing the mechanical properties of a material in laser-directed energy deposition (L-DED) (classified according to ASTM F2792-12a) is investigated. The source of the energy for melting the metal and forming a melting pool in this technology is a laser beam, and the working material is powder or wire fed into the melting zone. This additive manufacturing (AM) process appears to be based on the wellknown technology of laser cladding (LC). A distinctive feature of L-DED versus LC is the significant size of the cladding height ( $Z$ coordinate), the use of modern CAM production automation systems, and the introduction of artificial intelligence (AI).

In order to increase the attractiveness of this technology, new methods are being explored to influence the weld material to achieve unique or controllable properties. The principle of the process allows us to flexibly influence the properties of the grown material, and allows us to modify it.

Metal additive manufacturing allows us to print parts from iron, nickel, nickelchromium, and titanium alloys with a wide range of different chemical compositions [1-4]. 
Each AM technology has its own set of microstructural characteristics and mechanical properties [4-6]. Fusion-based metal AM is usually characterized by strong epitaxial growth from layer to layer, which leads to columnar grains along the building direction, and anisotropic properties with respect $X Y$ and $X Z$ planes [7-10].

It is known that the dendritic microstructure is one of the most frequent structures in the L-DED process [11,12]. This type of dendritic structure is influenced by different cooling rates during the solidification of the molten pool. Directed, long, first-order dendrites are formed on each track boundary due to the increased cooling rates. Closer to the middle of the track, a structure of second- and third-order dendrites is observed. The anisotropy of the material's property is a common condition for L-DED technology, due to the layer-by-layer building strategy. As a result, a characteristic columnar structure is formed in the building direction $[7,8]$.

There have been various studies looking into the control of the anisotropy of the properties through the chemical composition, material microstructure (columnar to equiaxed transition), and finally the topology optimization of the components (lattice and lightweight structures) [9-12]. Improving material properties by changing the chemical composition is the most effective and most obvious method, but it has its limitations. Classical technologies for the shaping of metal products-e.g., casting, rolling, and forging-can successfully process only certain alloys; also, with L-DED, the excessive content of some elements leads to the poor-quality deposition of the material and unsuitable shaping. A high content of elements such as $\mathrm{Cr}, \mathrm{Mo}, \mathrm{W}, \mathrm{V}$, and $\mathrm{C}$ can reduce the weldability of products, resulting in the formation of tracks with defects, porosity, and cracking [13,14]. When the chemical composition limit is reached and the desired properties have not been achieved, it is possible to apply additional approaches to affect the material's structure.

In metallurgy, the method of ultrasound-assistance (US) is well known, and is effectively used in the processes of the crystallization of molten metal during casting and arc welding, etc. [15-18]. The direct input of US leads to many non-linear effects, including acoustic flow and cavitation. Through these effects, sonication can reduce the porosity and homogenize the microstructure.

A review of the state-of-the-art application of ultrasound for laser cladding technology and L-DED showed that some researchers have already managed to combine ultrasonic exposure and L-DED. In [19], the relationship between the columnar dendritic microstructure and the power of vibration US welding of AISI 304 stainless steel with $316 \mathrm{~L}$ as an additive material was investigated. Their results show that an increase in US power from $0 \%$ to $90 \%$ leads to a decrease in the proportion of the columnar dendritic microstructure from $95 \%$ to $10 \%$ (Figure 1a) and, consequently, to a predominantly dendritic equiaxed and fine-grained microstructure. In [20-23], the authors studied the effect of US on structure formation in the L-DED process, and associated it with the laser deposition of Inconel 718, Ti-6Al-4V, Inconel 625 , and $\mathrm{Cr} 12 \mathrm{MoV}$ alloys. Also known is the work on the simultaneous exposure of laser cladding to an ultrasonic source, an alternating magnetic field, and a constant magnetic field [24]. The authors used a remote method of delivering ultrasonic exposure to the surfacing material using an ultrasonic beep. An important conclusion of the work is that the ultrasonic effect had a significant effect on the hardness of the deposit, while the effects of the electromagnetic fields were insignificant. This confirms the usefulness of the study of US treatment as one of the most effective methods of influencing the microstructure and properties of deposited metals.

In this paper, we study the behavior of $\mathrm{H} 13$ tool steel fabricated by direct laser deposition with the assistance of ultrasound (ultrasound-assisted L-DED). The schematic process of US-assisted L-DED is shown in Figure 1b. The steel substrate is exposed to ultrasonic vibrations, which, in turn, transmit these vibrations to the volume of molten metal and act on it during crystallization. 


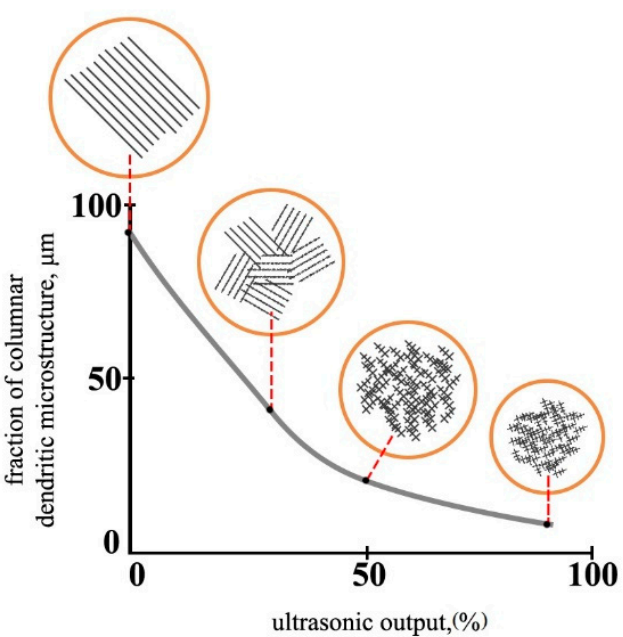

(a)

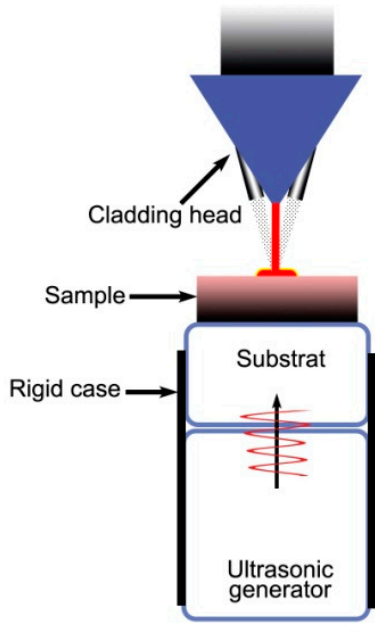

(b)

Figure 1. (a) Fraction of the columnar dendritic microstructure in the weld metal as a function of the US vibration (Adapted with permission from ref. [19]. Copyright 2007 WILEY). (b) Schematic of US-assisted L-DED.

AISI H13 steel is a tool steel with a carbon content of about $0.4 \%$, which has increased wear and heat resistance. This steel is used to manufacture injection molds for "soft" materials such as zinc, aluminum, and magnesium alloys; it is also used for hammers, and for press inserts for the hot deformation of structural steels. The decrease in anisotropic properties after L-DED and the fine structure of this steel may increase the life of such dies after repair and reconditioning. However, the successful suppression of the columnar grain structures by US during the AM of tool steel has not been reported to date. Furthermore, this article compares the US influence with the heat treatments used to homogenize the properties for different directions.

The purpose of this work is to determine the ways in which tool steel, which has a high hardness, is further affected by US in L-DED, which should likely increase its hardness and reduce the anisotropy in its properties. The scientific significance of this work lies in the study of the effect of US on H13 tool steel, and the assessment of the effect of US-assistance on the properties of this steel in comparison with various heat treatments. Furthermore, the study presents a novel design of a versatile device for in-situ US-assistance during L-DED.

\section{Materials and Methods}

\subsection{L-DED Processing}

Steel AISI H13 powder obtained by the gas atomization method with a particle size of $45-90 \mu \mathrm{m}(\mathrm{d} 10=53 \mu \mathrm{m}, \mathrm{d} 50=72 \mu \mathrm{m}, \mathrm{d} 90=91 \mu \mathrm{m})$ produced by TLS Technik (BitterfeldWolfen, Germany) was used in this study. As shown in Figure 2, the powder's morphology is spherical, and the chemical composition of the powder is presented in Table 1.

The experiment was carried out on the developed L-DED laboratory setup, which consists of the following components: a continuous ytterbium fiber laser IPG LS-3 (Fryazino, Moscow region, Russia) with a center wavelength range of $1070 \pm 10 \mathrm{~nm}$, an automatic powder feeder with two feed tanks, a "Plakart" (Gtv Verschleissschutz GmbH, Luckenbach, Germany) with an adjustable powder feed rate, cladding head KUKA MWO-1 (KUKA, Augsburg, Germany) with three powder nozzles and adjustable collimator, and 6-axis Fanuc M20i robot (FANUC, Oshino, Japan), which is responsible for moving the cladding head. The specifications of this setup are similar to those for the commercial use of LDED technology. The samples were manufactured according to the printing strategy of rectangular samples, and with the coordinate system shown in Figure 3a. 


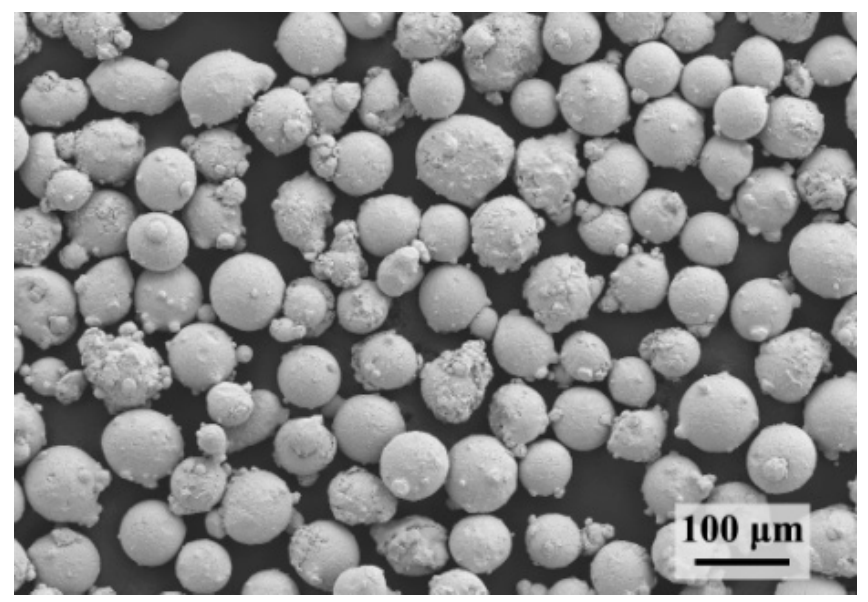

Figure 2. SEM image showing the morphology of H13 powder.

Table 1. Chemical composition of steel $\mathrm{H} 13(\mathrm{wt} \%)$, according to the delivery certificate.

\begin{tabular}{ccccccccc}
\hline Elements & Fe & C & Si & Mn & Cr & Mo & V \\
\hline value & bal. & 0.40 & 1.00 & 0.48 & 5.30 & 1.30 & 1.00 \\
\hline
\end{tabular}

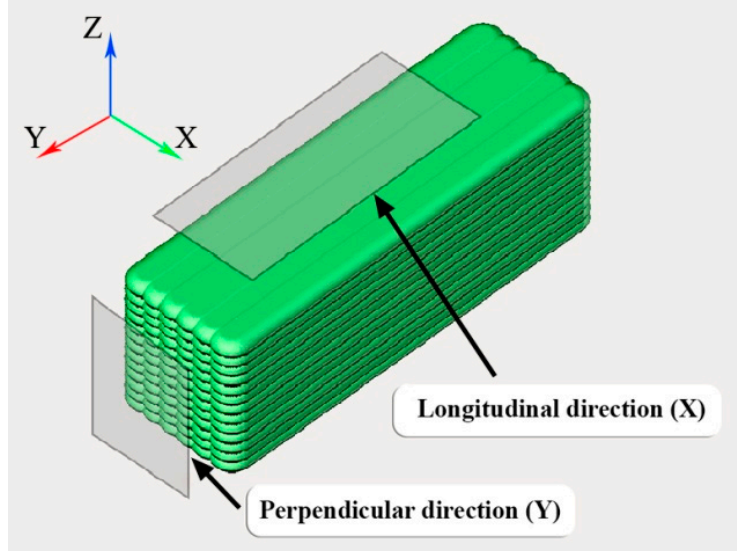

(a)

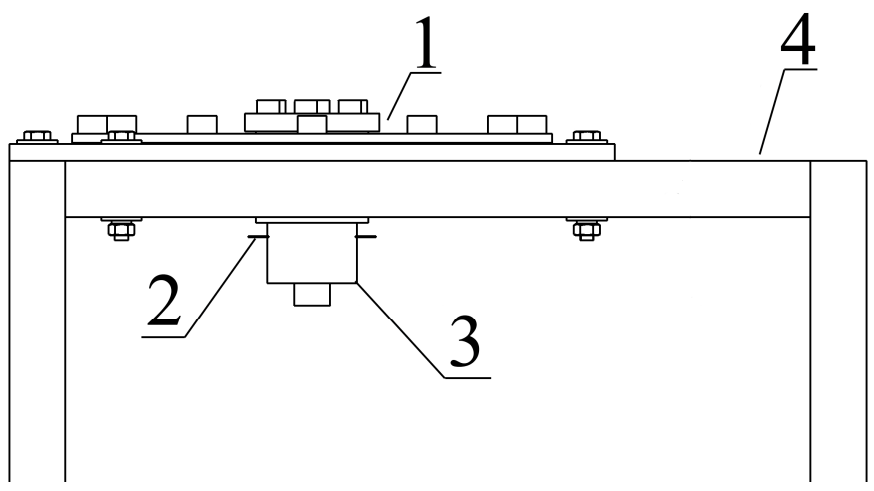

(c)

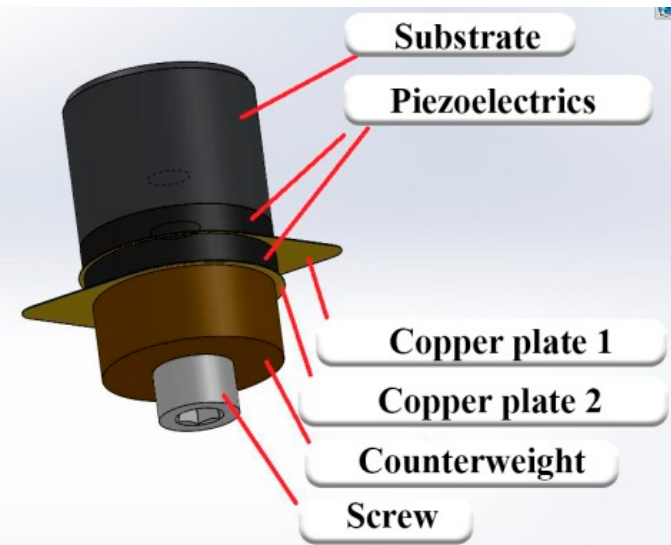

(b)

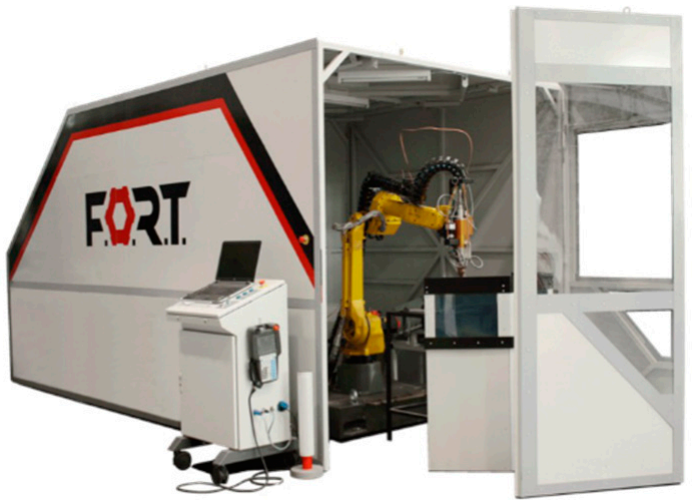

(d)

Figure 3. (a) Sample showing the multitrack printing strategy; (b) layout of the substrate with US-assisted L-DED; (c) scheme of the US substrate device, where $\mathbf{1}$ is the front side with a substrate for cladding, $\mathbf{2}$ is the cooling circuit, $\mathbf{3}$ is the bottom of the case with the piezoelectrics, and 4 is the working table; (d) the image of the experimental setup. 
A novel design was developed, featuring a US source-substrate, which allows the transmission of US vibrations from the generator with a frequency of $28 \mathrm{kHz}$ and a power of $50 \mathrm{~W}$ (Figure 3b,c). This frequency was determined by the initial characteristics of the ultrasonic generator.

A device for US assistance on a substrate consists of ceramic piezoelectrics, which are connected to a US generator through copper plates (Figure 3c). In order to avoid the destruction of ceramic elements during cladding (due to the overheating of US elements) the device was equipped with a cooling circuit. The performance of the device was verified by measuring the intensity of the US radiation, as well as the exposure to liquids.

Two samples were printed on the substrate, with and without US exposure. The effect of additional heat dissipation on such a substrate is much greater than when printing on a conventional substrate without a cooling circuit, which affects the structure of the material. Thus, for the experimental verification, the sample without US or the water cooling of the substrate was also included. The deposition of the samples using L-DED technology was carried out according to the following parameters: a laser power of $1200 \mathrm{~W}$, a laser beam width of $3 \mathrm{~mm}$, a robot speed of $12 \mathrm{~mm} / \mathrm{s}$, a powder feed of $15 \mathrm{~g} / \mathrm{min}$, argon protection at $20 \mathrm{~L} / \mathrm{min}$, carrier gas argon at $6 \mathrm{~L} / \mathrm{min}, 50 \%$ overlapping tracks, a layer height of $0.6 \mathrm{~mm}$, and a water flow rate for substrate cooling of $20 \mathrm{~L} / \mathrm{h}$. These parameters have been tested on this steel many times in previous works for this installation in order to obtain the maximum density of the deposit.

Heat treatment was carried out in a programmable muffle furnace, KLS-1100X (LLC "EVS", St. Petersburg, Russia), without a protective atmosphere. The first type of heat treatment annealing (HT1) consisted of heating up to $900^{\circ} \mathrm{C}$ degrees and holding for $2 \mathrm{~h}$, and then cooling in air. The second heat treatment was quenching with tempering (HT2) consisting of heating to $1020{ }^{\circ} \mathrm{C}$ degrees with quenching in oil, followed by tempering at $580{ }^{\circ} \mathrm{C}$ degrees for $2 \mathrm{~h}$ and air cooling.

\subsection{Characterization}

The L-DED manufactured samples were cut from the substrate. The metallographic preparation of the samples included grinding, polishing down to $1 \mu \mathrm{m}$, and subsequent chemical etching by a $10 \mathrm{~mL} \mathrm{H} \mathrm{H}_{2} \mathrm{O}, 30 \mathrm{~mL} \mathrm{HCl}$, and $1.5 \mathrm{~mL} \mathrm{H}_{2} \mathrm{O}_{2}$ etchant. The structure was studied using an optical microscope.

The hardness measurement of the thin sections was carried out by the Vickers method at a load of $0.5 \mathrm{~kg}$, and by holding for $10 \mathrm{~s}$.

In order to identify the phases of X-ray diffraction (XRD), they were carried out on a Bruker D8 Advance diffractometer (Billerica, MA, USA) with copper radiation $(\mathrm{CuK} \alpha=1.5418 \AA)$. The structural parameters of the samples were refined by the Rietveld method using TOPAS ver.5.0 software.

\section{Results and Discussion}

\subsection{Effect of US on the Microstructural Characteristics}

The appearance of a cladded sample made of H13 steel on a platform with US is shown in Figure 4. The structure was studied in two directions: perpendicularly (Y), corresponding to the building direction, and parallel $(\mathrm{X})$ to the substrate.

The microstructure of the original sample (without US) is shown in Figure 5, and the sample with US is shown in Figure 6. The study of the structure in the perpendicular direction was carried out over the entire cross-section of the sample, which makes it possible to characterize the entire structure of the sample, from the bottom of the surfacing to the top. In the longitudinal direction, the study of the structure took place at the base of the surfacing in the zone 1-2 $\mathrm{mm}$ above the substrate, where there is no longer any diffusion of elements from the substrate material. All of the obtained conclusions about the material in the parallel direction are valid for the material in this area, which also affects the area of interest for the cladding of functional coatings with a thickness of 1-2 mm. 


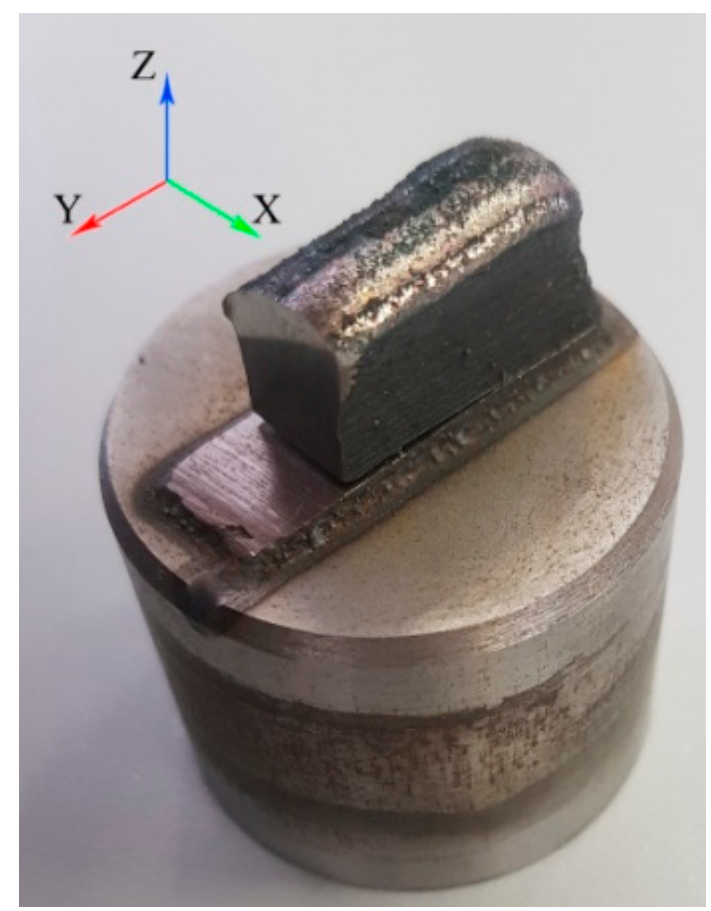

Figure 4. H13 steel (cross-section) made on the substrate with US-assisted L-DED.

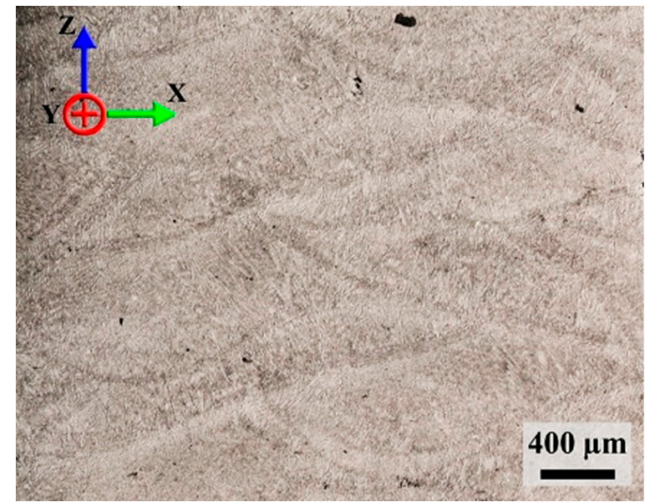

(a)

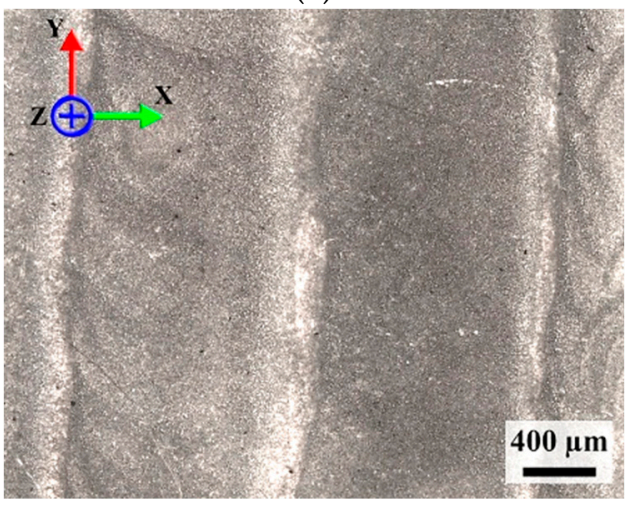

(c)

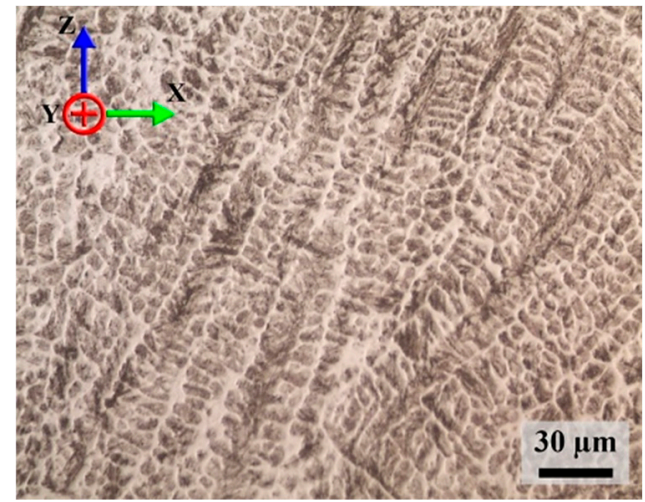

(b)

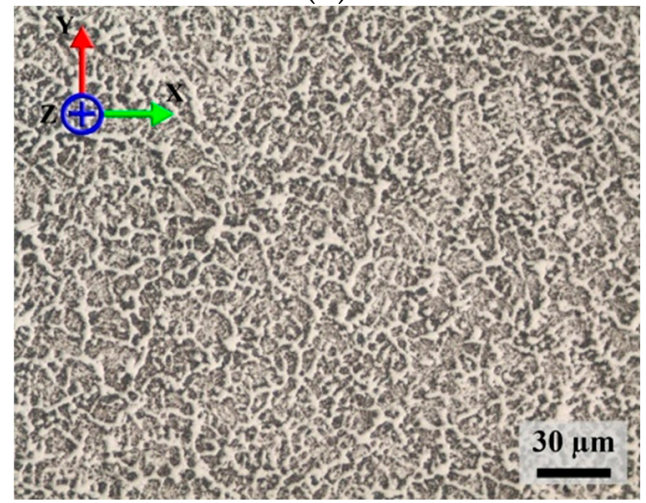

(d)

Figure 5. Microstructure of the original H13 steel sample L-DED manufactured without US, where $(\mathbf{a}, \mathbf{b})$ are the perpendicular direction $(\mathbf{Y})$, in line with the building direction, and $(\mathbf{c}, \mathbf{d})$ are the longitudinal direction $(\mathbf{X})$. 


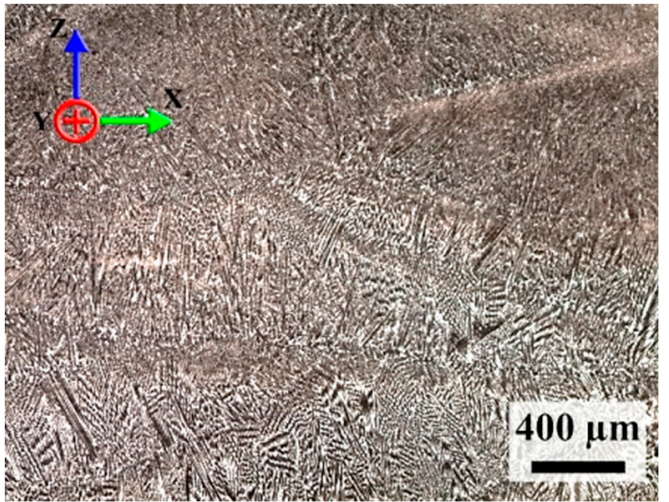

(a)

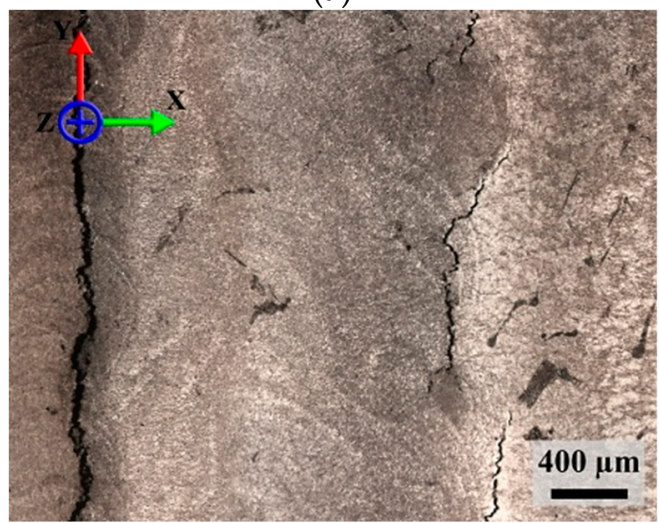

(c)

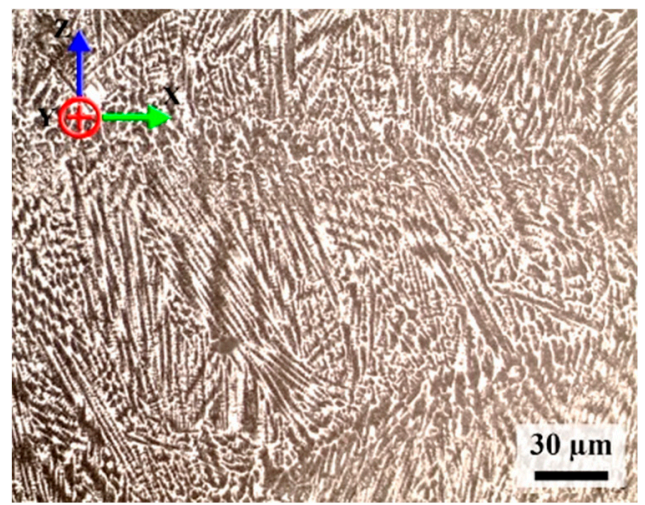

(b)

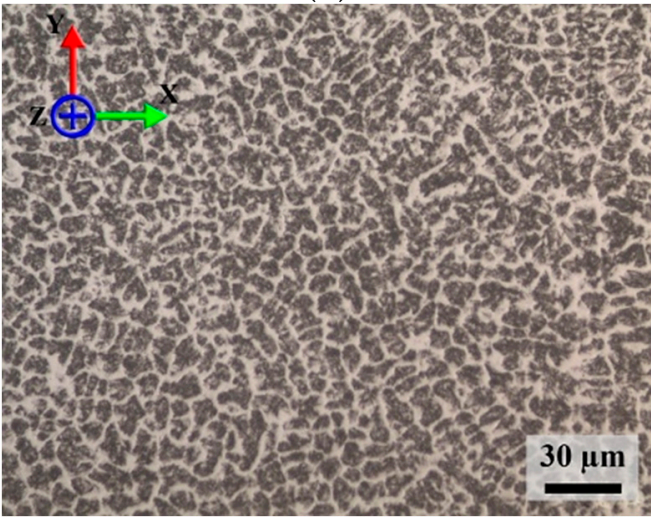

(d)

Figure 6. Microstructure of a H13 steel sample L-DED manufactured with US, where $(\mathbf{a}, \mathbf{b})$ are the perpendicular direction $(\mathbf{Y})$, in line with the building direction, and (c,d) are the longitudinal direction $(\mathbf{X})$.

The figures show the characteristic anisotropic and dendritic structure (Figure 5b). At $\times 50$ zoom (Figure $5 \mathrm{a}$ ), the boundaries between the tracks are visible. In the perpendicular direction, there are mainly first-order dendrites, with the growth direction towards the heat removal zones, i.e., the track boundaries (Figure $5 b$ ). In the parallel direction (c-d), variously oriented third-order dendritic grains with an average size of $30 \mu \mathrm{m}$ are observed.

The macrostructure of the sample with US (Figure 6a) is similar to that without the US (Figure 5a). However, at a larger magnification (b, d), differently directed first-order dendrites can be observed. The orientation of the dendrites tracks the melt pool boundaries (cooling zones). The length of the dendrites is less than that of the sample without US. The size of the third-order dendrites in the parallel direction (Figure 6d) decreased twice, to $15-20 \mu \mathrm{m}$. The homogeneity of the grain morphology significantly increased. The morphologies of the cracks shown in Figure $6 \mathrm{c}$ are clearly cold cracking, indicating that those cracks are initiated by stress and distortion. Excessive thermal stresses accumulate in the deposited material while standard operating modes of the L-DED installation are used. Eventually, the additional internal stresses from US led to the formation of cracks in the vulnerable places between the tracks. Confirmation and reasons for the negative effect of ultrasound on the connection between neighboring tracks were found in the work [25]; the authors concluded that this was the impact of ultrasound, which forms a large number of cavitation bubbles inside the bath melt, coming to the surface and leading to increased stress inside the track. Furthermore, the authors expressed the opinion that these bubbles increase the temperature inside the track due to the thermal energy produced by the friction of the liquid metal.

Figure 7 shows XRD spectrums of the samples obtained by L-DED without USassistance. The main phase is $\alpha-\mathrm{Fe}$, and a small amount of $\gamma$-Fe was detected in the 
longitudinal direction $(\mathrm{Y})$, probably due to the diffusion of lower-layer elements with a steel substrate. The Rietveld method (using the TOPAS5 software) was used to refine the structural parameters: the microstrain $\left(\mathrm{e}_{0}\right)$, the coherent scattering region (CSR), and the lattice parameter of the unit cell (a). Significant microstrain $\mathrm{e}_{0}$ was found in all of the samples, which indicates significant residual stresses after surfacing. Significant differences in the effect of US on this parameter were not found. The differences between the CSR values for the samples without sonication indicate the possible presence of isotropy in the grain size for two different directions, which is associated with directed dendrite growth. In samples with US, it can be concluded that there are no significant differences in the grain size for the two directions of research according to the CSR data.

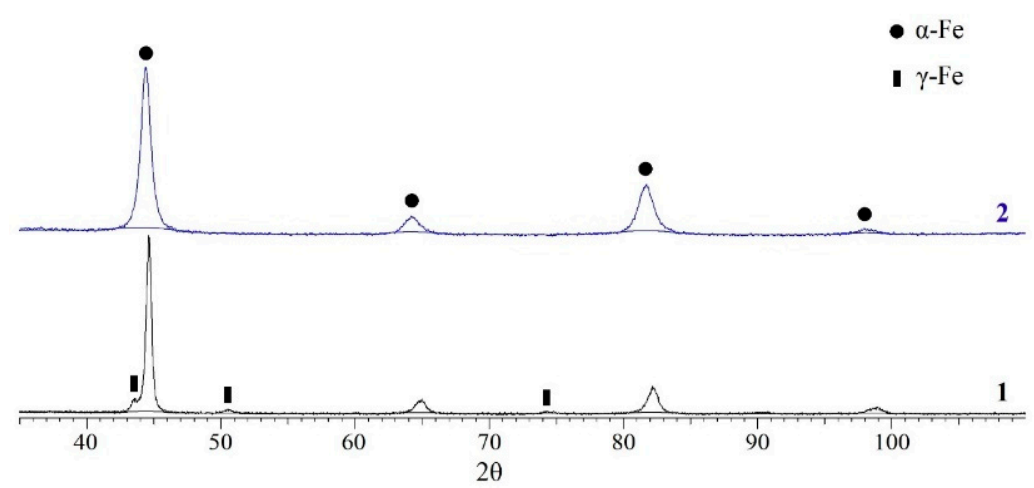

Figure 7. XRD of L-DED samples in the perpendicular (1) and longitudinal (2) directions without US-assisted treatment.

The XRD of the L-DED sample manufactured with US is shown in Figure 8 . The phase composition of the sample is characterized by a single phase, $\alpha$-Fe. The values of the CSR size and the unit cell parameter are almost the same, and are between the values in the parallel and longitudinal directions in the sample without US (Table 2), which indicate the more isotropic structure of US-assisted L-DED samples.

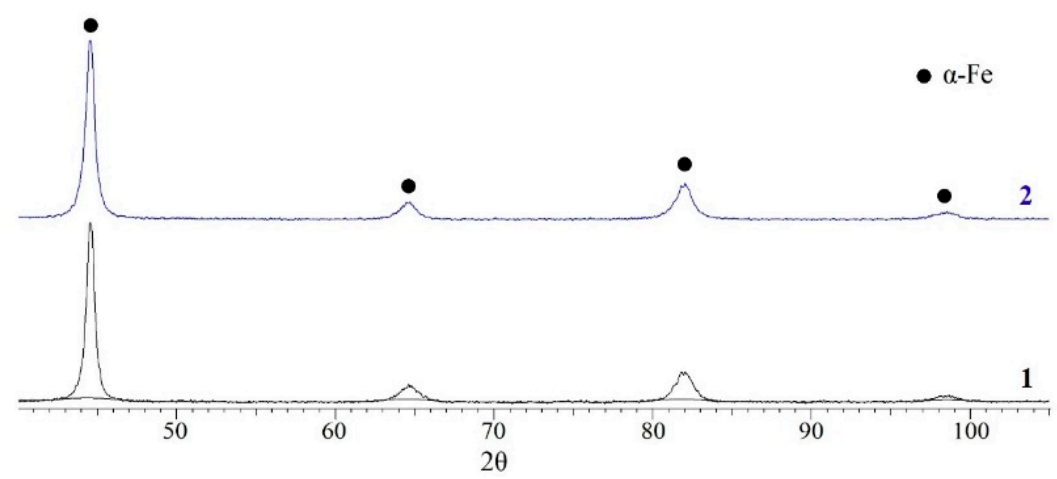

Figure 8. XRD of L-DED samples in the perpendicular (1) and longitudinal (2) directions with US-assisted treatment.

Table 2. XRD Rietveld results showing the structural parameters.

\begin{tabular}{cccc}
\hline Sample & a, (̊̊) & CSR, $(\mathbf{n m})$ & $\mathbf{e}_{\mathbf{0}}$ \\
\hline without US_perp & 2.891 & 14 & 0.005 \\
without US_long & 2.874 & $>200$ & 0.004 \\
with US_perp & 2.883 & 42 & 0.005 \\
with US_long & 2.883 & 48 & 0.006 \\
\hline
\end{tabular}

The larger globular porosity of the "keyhole" type was found in the H13 tool steel samples manufactured without US (Figure 9). This type of defect is further discussed in [23]. 


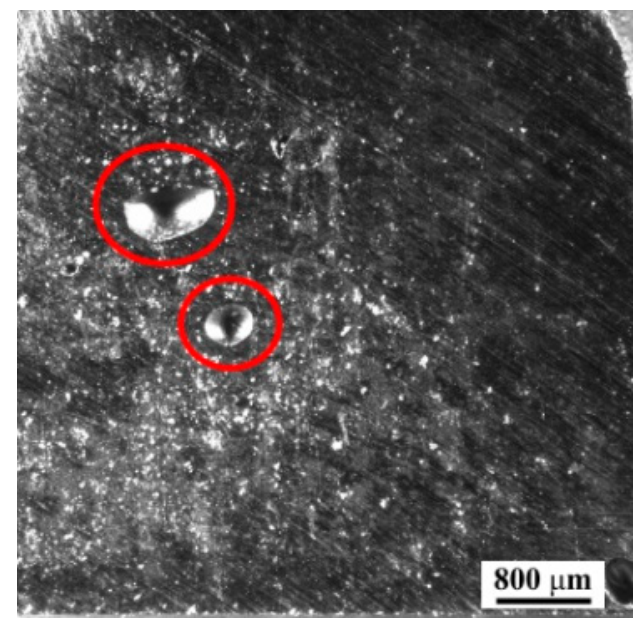

Figure 9. Porosity (keyholes) in the samples without US.

The keyholes were not found in the US-assisted samples, which made it possible to manufacture 0.5-mm thick specimens, and to perform tensile testing. Because H13 steel is susceptible to the formation of keyhole defects, one of the effective applications of US-assisted L-DED could thus be the cladding of thin wall parts.

The density of the samples was further measured in order to verify the densification results, and to provide a quantitative assessment. The hydrostatic weighing of three different parts of the sample was carried out using the Archimedes method (Figure 10). As can be seen, the US-assisted samples showed an increase in density from $7.68 \mathrm{~g} / \mathrm{cm}^{3}$ to $7.75 \mathrm{~g} / \mathrm{cm}^{3}$, and brought the density value closer to $7.60 \mathrm{~g} / \mathrm{cm}^{3}$, which is the defect-free value of a fully compacted sample.

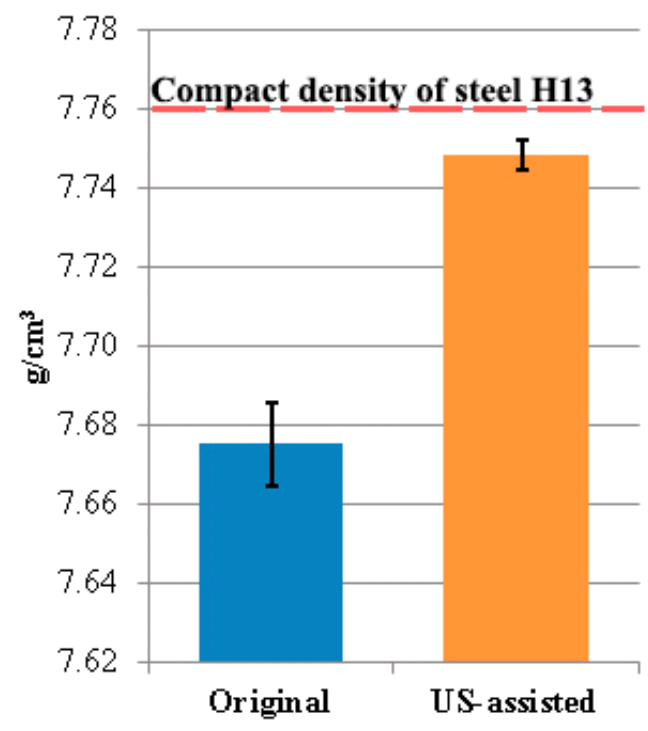

Figure 10. Effect of US on the density (as measured by the Archimedes method).

\subsection{Effect of Heat Treatment on the Microstructural Characteristics}

Annealing (HT1) and quenching with tempering (HT2) influenced the macro- and micro-structure of the H13 steel. Optical images of the macrostructure at $\times 50$ magnifications (Figure 11) showed that the interfaces between the tracks almost completely disappeared and recrystallized, but even after annealing, the macrostructure with melt pools and track interfaces remained on all of the samples and directions. 


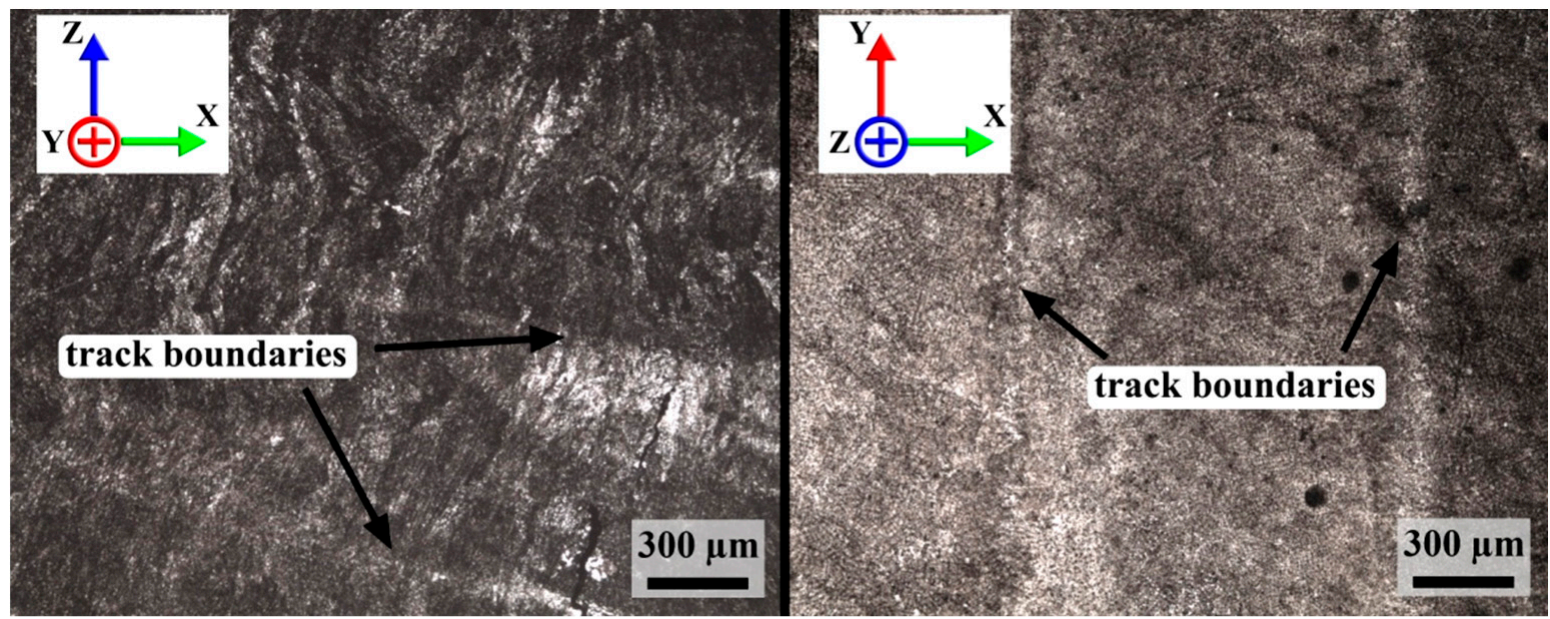

(a)

(b)

Figure 11. Macrostructure of the original sample after annealing (HT1), where (a) is the perpendicular direction $(\mathbf{Y})$ and $(\mathbf{b})$ is the longitudinal direction $(\mathbf{X})$.

All of the types of obtained microstructures after heat treatment are shown in the diagram at $\times 500$ magnification (Figure 12).

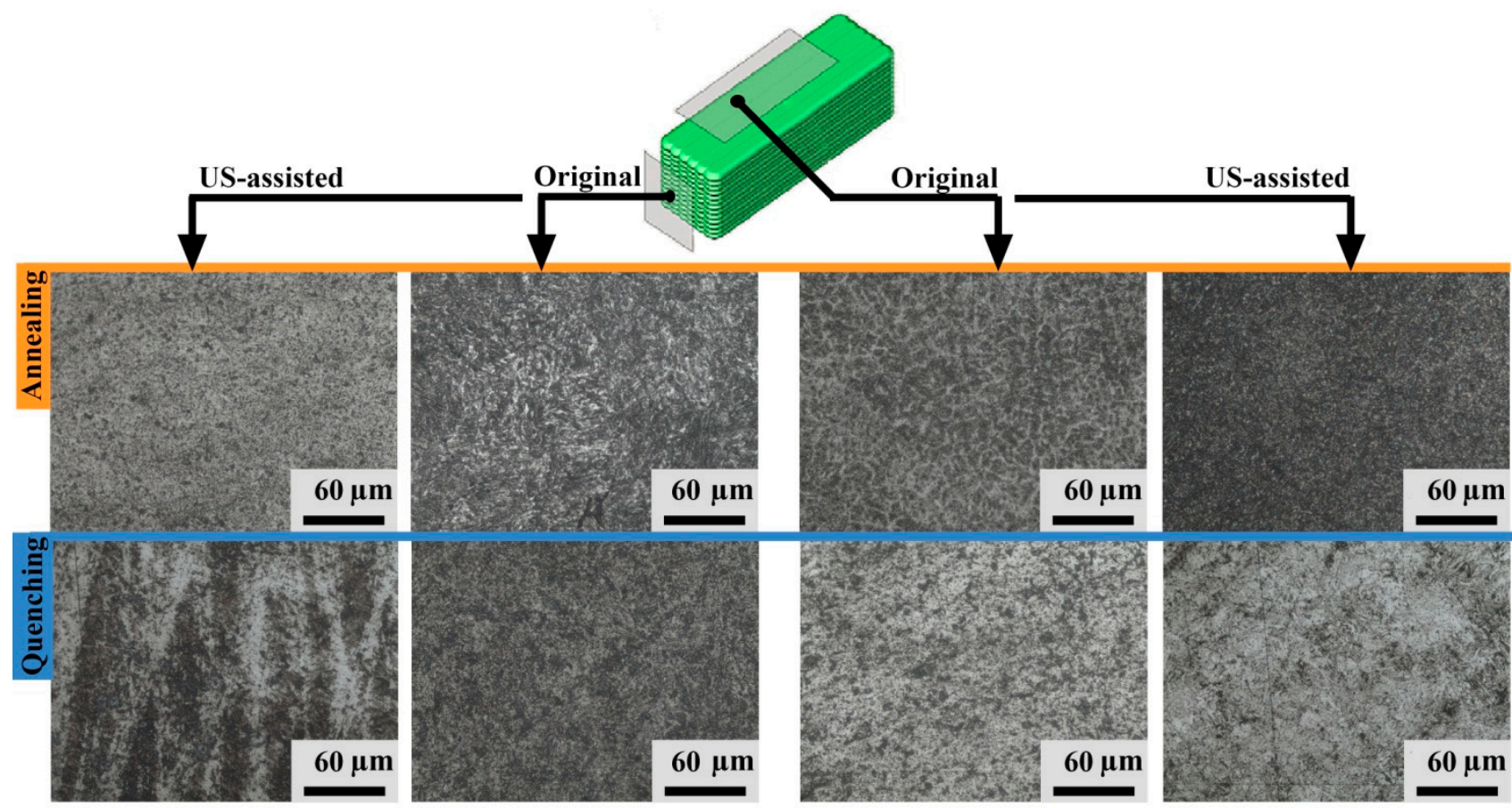

Figure 12. Microstructure of the samples with and without US assistance after heat treatment, in the longitudinal and perpendicular directions.

The annealed microstructure consists of a ferrite matrix with carbides. This is confirmed by the hardness results. It can also be concluded that the recrystallization process was incomplete due to the significantly higher hardness of the original sample in the perpendicular direction compared to the longitudinal direction (the difference was $20 \%$ ). For the specimens after quenching with tempering, the microstructure was mainly tempered martensite, which is also consistent with the hardness values. 


\subsection{Effect of US and Heat Treatment on the Hardness Behavior}

The hardness results are shown in Figure 13. As can be seen, the hardness for the original sample without US assistance was $581 \pm 3$ HV0.5 (54 HRC) for the longitudinal direction and $700 \pm 4 \mathrm{HV} 0.5$ (59 HRC) for the perpendicular direction, resulting in a $20 \%$ difference. For samples with US assistance, the hardness values are more isotropic, at $640 \pm 18$ HV0.5 and $649 \pm 11$ HV0.5 (both 56 HRC), respectively, showing a difference of only about $2 \%$. Different mechanical properties in the perpendicular and longitudinal directions are typical for additive technologies due to the layer-by-layer method of building. The significant difference in hardness in the two directions without modification practically disappears with the addition of US. Thus, it can be concluded that US assistance L-DED results in the disappearance of the anisotropic hardness properties, which is also confirmed by the results of the XRD analysis. However, a decrease in hardness was found for the ultrasonicated specimens, which is an unexpected result. According to the Hall-Petch relation, with a decrease in the structural components, the yield strength increases, and there is a direct relationship between the yield strength and hardness. First of all, it is necessary to pay attention to the equality of the average hardness values for the two directions. This means that US increased the hardness in the longitudinal direction, and decreased it in the perpendicular direction. This could have happened due to an increase in internal stresses; according to the previously determined value of microstrain $\mathrm{e}_{0}$, an increase in this parameter can be noted, and for the longitudinal direction it is greater than for the perpendicular direction. The accumulation of micropores from cavitation, which are not visible on sections due to their small size, could cause a decrease in hardness for the sample in the perpendicular direction.

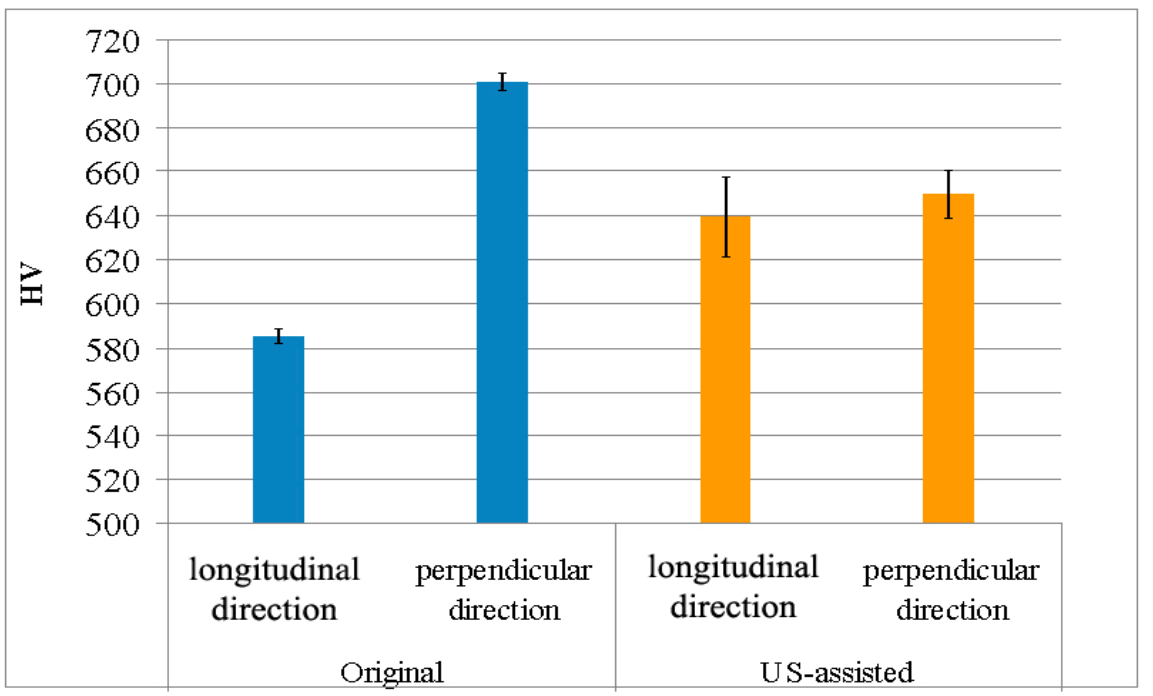

Figure 13. Effect of US on the Vickers hardness (HV0.5), shown for two directions: the longitudinal and perpendicular directions with respect to the substrate.

The data obtained were evaluated by methods of mathematical statistics, namely, by calculating Student's $t$-tests for two independent samples. The $t$-tests were calculated for two directions in the initial state of the material, and for two directions after sonication. The calculated $t$-test for samples from two directions of the original sample is $t=31.5$, and for the US-assisted sample $t=0.2$. The $t$-critical for degrees of freedom $f=4$ and $95 \%$ confidence interval is 2.78 . The calculated value of $t$ of the criterion is greater than the critical value for the original sample and less than the US-assisted sample, which rejects the hypothesis of the equality of the mean values for the first case, and confirms the hypothesis of the equality of the mean values for the second case at a given significance.

Heat treatment significantly influenced the hardness of the samples without USassisted treatment and with US-assisted treatment. The hardness values after heat treat- 
ments for the two printing directions ( $X$ and $Y$ ) of the original sample and the sample with US treatment are shown in Figure 14.

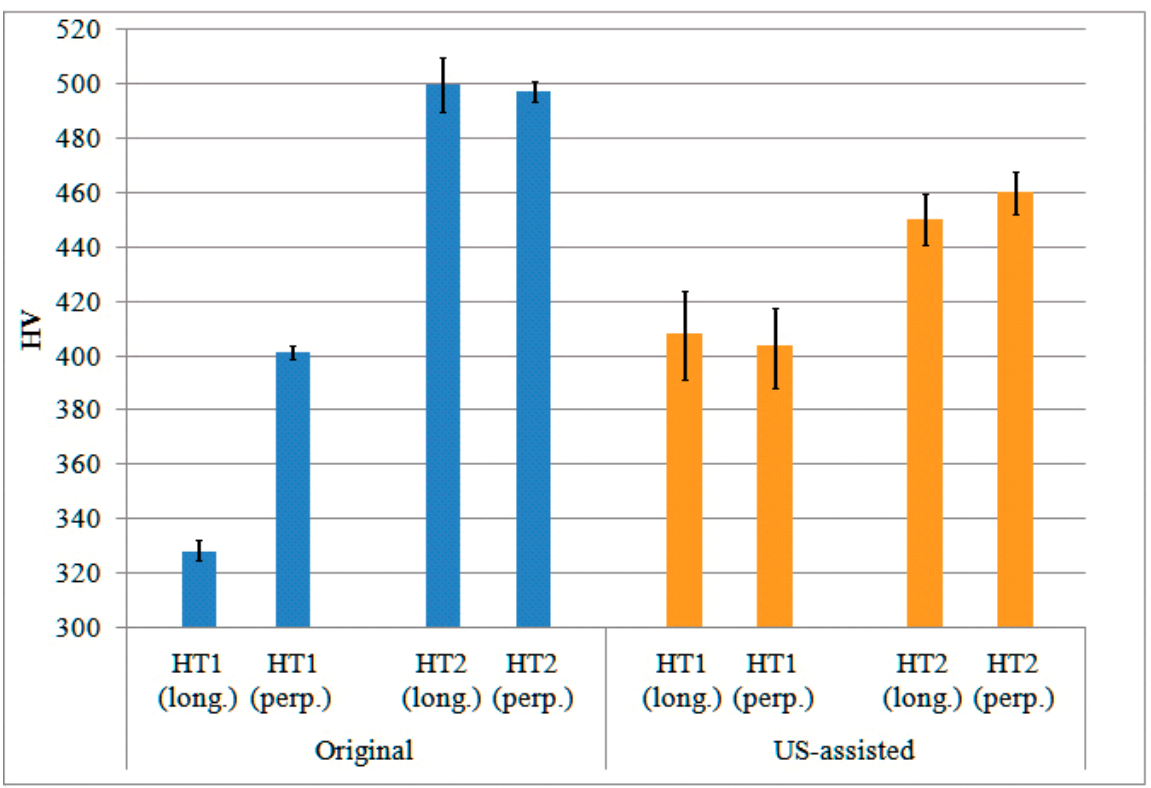

Figure 14. Effect of heat treatment on the Vickers hardness (HV0.5), shown for two types of heat treatment and for two directions: longitudinal and perpendicular with respect to the substrate.

As a result of annealing (HT1) to eliminate internal stresses after L-DED and USassisted L-DED, the samples without US assistance and with US assistance showed practically the same hardness of 401-408 HV0.5 (41-42 HRC), except for the original sample in the longitudinal direction, with a hardness of 330 HV0.5 (34 HRC). This indicates an incomplete recrystallization process in these samples. It is likely that with an increase in the HT time, the hardness of these samples should drop to at least this value. In all probability, the hardness of these samples with increasing heat treatment times should drop to at least this value. However, US equalized the property of hardness for two directions; therefore, for these samples, the decrease in hardness with increasing exposure time should be uniform, regardless of the direction of the exposure. Quenching with tempering (HT2) for the samples with US assistance showed a lower hardness than that for the sample without such treatment. The reason for this difference is that the inheritance of the structural anisotropy has been preserved. The hardness in this direction for samples without heat treatment and US treatment shows the maximum value, while the sample with US treatment has increased isotropy and hardness. In general, quenching and tempering lowered the hardness of the H13 samples obtained by the L-DED method, which could also indicate the significant accumulation of internal stresses.

By analogy, as for the samples without heat treatment, a test was performed for the equality of the average values by Student's $t$-test. The pairs' original HT1 (longitudinal), HT1 (perpendicular), and other values were compared according to the pairs shown in Figure 14. Only the criterion $t=14.1$ for the pair of the original HT1 (longitudinal) and HT1 (perpendicular) turned out to be higher than the critical $2.78(\alpha=95 \%, f=4)$. The average values of the remaining pairs of samples were considered equal for a given significance. The main conclusion is that it is possible to provide the same mechanical properties in terms of hardness in the two directions studied here, with either the help of heat treatment or US-assisted L-DED. 


\title{
4. Conclusions
}

This study demonstrated a promising application of US assistance in the L-DED of $\mathrm{H} 13$ tool steel, which enables the formation of an equiaxed structure and improves the microstructural and mechanical homogeneity in samples of small heights:

- H13 tool steel shows a more refined equiaxed microstructure with an increased number of third-order dendrites.

- There are no "keyhole" defects, which are often present in the molten conventional L-DED material.

- It was found that US-assisted L-DED allows us to obtain a more isotropic structure with an equal size of the coherent scattering region in two printing directions, and to reduce the residual stresses in the material.

- The difference in the anisotropy of the properties in hardness is 1\% with 636 and $640 \mathrm{HV}$ (56 HRC both) for the perpendicular and parallel directions, respectively. Without US assistance, it is $581 \pm 3$ HV0.5 (54 HRC) for the longitudinal direction and $700 \pm 4$ HV0.5 (59 HRC) for the perpendicular direction, resulting in a $20 \%$ difference.

- Structural inheritance from the material modification induced by US affects the result of the heat treatment. Based on the obtained hardness data, it was noted that HT2 heat treatment can also result in a decrease in the anisotropy of the properties, similarly to the effect of US assistance.

- Although US assistance showed very promising effects on the reduction of anisotropy and residual stresses, an adverse effect was also found in this work. It was found in the weakening of the inter-track bonding in a parallel direction and the formation of cracks at the boundary of two subsequent tracks. The US-assisted L-DED process parameters should thus be further optimized.

\begin{abstract}
Author Contributions: Conceptualization, D.M. and A.P.; data curation, D.M., A.O. and A.K.; funding acquisition, V.P.; investigation, S.I. and A.K.; methodology, D.M. and S.I.; project administration, A.P.; resources, S.I.; software, A.O.; supervision, V.P.; validation, A.O. and V.P.; visualization, A.O.; writing-original draft, S.I.; writing-review and editing, D.M., A.P. and V.P. All authors have read and agreed to the published version of the manuscript.
\end{abstract}

Funding: This research was funded by the Russian Science Foundation, grant number 19-79-30002.

Institutional Review Board Statement: Not applicable.

Informed Consent Statement: Not applicable.

Data Availability Statement: The data presented in this study are available on request from the corresponding author.

Conflicts of Interest: The authors declare no conflict of interest.

\section{References}

1. Stevens, E.L.; Toman, J.; To, A.C.; Chmielus, M. Variation of hardness, microstructure, and Laves phase distribution in direct laser deposited alloy 718 cuboids. Mater. Des. 2017, 119, 188-198. [CrossRef]

2. Clark, D.; Whittaker, M.T.; Bache, M.R. Microstructural characterization of a prototype titanium alloy structure processed via direct laser deposition (DLD). Metall. Mater. Trans. B Process. Metall. Mater. Process. Sci. 2012, 43, 388-396. [CrossRef]

3. Dinda, G.P.; Dasgupta, A.K.; Mazumder, J. Laser aided direct metal deposition of Inconel 625 superalloy: Microstructural evolution and thermal stability. Mater. Sci. Eng. A 2009, 509, 98-104. [CrossRef]

4. Guo, P.; Zou, B.; Huang, C.; Gao, H. Study on microstructure, mechanical properties and machinability of efficiently additive manufactured AISI 316L stainless steel by high-power direct laser deposition. J. Mater. Process. Technol. 2017, 240, 12-22. [CrossRef]

5. Wang, L.; Xue, J.; Wang, Q. Correlation between arc mode, microstructure, and mechanical properties during wire arc additive manufacturing of 316L stainless steel. Mater. Sci. Eng. A 2019, 751, 183-190. [CrossRef]

6. Liverani, E.; Toschi, S.; Ceschini, L.; Fortunato, A. Effect of selective laser melting (SLM) process parameters on microstructure and mechanical properties of 316L austenitic stainless steel. J. Mater. Process. Technol. 2017, 249, 255-263. [CrossRef]

7. Wang, Q.; Zhang, S.; Zhang, C.H.; Wu, C.L.; Ren, L.; Wang, J.Q.; Chen, J. Functionally Graded Stainless Steel Fabricated by Direct Laser Deposition: Anisotropy of Mechanical Properties and Hardness. Acta Metall. Sin. 2018, 31, 19-26. [CrossRef] 
8. Lu, J.; Chang, L.; Wang, J.; Sang, L.; Wu, S.; Zhang, Y. In-situ investigation of the anisotropic mechanical properties of laser direct metal deposition Ti6Al4V alloy. Mater. Sci. Eng. A 2018, 712, 199-205. [CrossRef]

9. Popovich, V.A.; Borisov, E.V.; Sufiyarov, V.S.; Popovich, A.A. Tailoring the Properties in Functionally Graded Alloy Inconel 718 Using Additive Technologies. Met. Sci. Heat Treat. 2019, 60, 701-709. [CrossRef]

10. Deev, A.A.; Kuznetcov, P.A.; Petrov, S.N. Anisotropy of Mechanical Properties and its Correlation with the Structure of the Stainless Steel 316L Produced by the SLM Method. Phys. Procedia 2016, 83, 789-796. [CrossRef]

11. Parimi, L.L.; Ravi, G.A.; Clark, D.; Attallah, M.M. Microstructural and texture development in direct laser fabricated IN718. Mater. Charact. 2014, 89, 102-111. [CrossRef]

12. Shamsaei, N.; Yadollahi, A.; Bian, L.; Thompson, S.M. An overview of Direct Laser Deposition for additive manufacturing; Part II: Mechanical behavior, process parameter optimization and control. Addit. Manuf. 2015, 8, 12-35. [CrossRef]

13. Richards, N.L.; Chaturvedi, M.C. Effect of minor elements on weldability of nickel base superalloys. Int. Mater. Rev. 2000, 45, 109-129. [CrossRef]

14. Talaş, S. The assessment of carbon equivalent formulas in predicting the properties of steel weld metals. Mater. Des. 2010, 31, 2649-2653. [CrossRef]

15. Watanabe, T.; Shiroki, M.; Yanagisawa, A.; Sasaki, T. Improvement of mechanical properties of ferritic stainless steel weld metal by US vibration. J. Mater. Process. Technol. 2010, 210, 1646-1651. [CrossRef]

16. Gorunov, A.I.; Nyukhlaev, O.A.; Gilmutdinov, A.K. Investigation of microstructure and properties of low-carbon steel during US-assisted laser welding and cladding. Int. J. Adv. Manuf. Technol. 2018, 99, 2467-2479. [CrossRef]

17. da Cunha, T.V.; Bohórquez, C.E.N. US in arc welding: A review. Ultrasonics 2015, 56, 201-209. [CrossRef]

18. Sun, Q.J.; Lin, S.B.; Yang, C.L.; Zhao, G.Q. Penetration increase of AISI 304 using US assisted tungsten inert gas welding. Sci. Technol. Weld. Join. 2009, 14, 765-767. [CrossRef]

19. Cui, Y.; Xu, C.; Han, Q. Microstructure Improvement in Weld Metal Using US Vibrations. Adv. Eng. Mater. 2007, 9, 161-163. [CrossRef]

20. Ning, F.; Hu, Y.; Liu, Z.; Cong, W.; Li, Y.; Wang, X. US Vibration-Assisted Laser Engineered Net Shaping of Inconel 718 Parts: A Feasibility Study. Procedia Manuf. 2017, 10, 771-778. [CrossRef]

21. Todaro, C.J.; Easton, M.A.; Qiu, D.; Zhang, D.; Bermingham, M.J.; Lui, E.W.; Brandt, M.; StJohn, D.H.; Qian, M. Grain structure control during metal 3D printing by high-intensity US. Nat. Commun. 2020, 11, 142. [CrossRef] [PubMed]

22. Zhou, J.; Xu, J.; Huang, S.; Hu, Z.; Meng, X.; Fan, Y. Microstructure and mechanical properties of Cr12MoV by US vibration-assisted laser surface melting. Mater. Sci. Technol. 2017, 33, 1200-1207. [CrossRef]

23. Masaylo, D.; Igoshin, S.; Popovich, A.; Popovich, V. Effect of process parameters on defects in large scale components manufactured by direct laser deposition. Mater. Today Proc. 2020, 30, 665-671. [CrossRef]

24. Hu, G.; Yang, Y.; Lu, X.; Li, J. A study on the influence mechanism and optimization of physical field parameters of electromagneticultrasonic compound field-assisted laser cladding technology. Weld. World 2021, 65, 1687-1700. [CrossRef]

25. Yang, Z.; Zhu, L.; Wang, S.; Ning, J.; Dun, Y.; Meng, G.; Xue, P.; Xu, P.; Xin, B. Effects of ultrasound on multilayer forming mechanism of Inconel 718 in directed energy deposition. Addit. Manuf. 2021, 48, 102462. [CrossRef] 